\title{
A PINTURA CONTEMPORÂNEA COMO POSSIBILIDADE FORMADORA
}

Reinaldo Gomes de Arruda ${ }^{1}$

\section{Resumo}

A abordagem ontológica é uma necessidade fundamental para a compreensão $\mathrm{da}$ arte e da linguagem. $\mathrm{O}$ ensino da arte como cultura e linguagem no contexto escolar propicia a formação estética e artística, importante para a percepção das coisas do mundo. Desse modo, esta é uma pesquisa de cunho bibliográfico com ênfase no estudo e na análise do pensamento de Merleau-Ponty acerca da pintura com o objetivo de compreender o pensamento de Maurice Merleau-Ponty sobre a pintura. Foram agregados nesta pesquisa alguns estudiosos da filosofia, especificamente da estética, bem como teóricos específicos da educação para articular as possíveis contribuiçóes da experiência artística no contexto escolar. Nesse sentido, compreende-se que a arte necessita ser democratizada, ou seja, ensinada a todos com o compromisso de ampliar os domínios estéticos e artísticos.

Palavras-chave: Ensino da arte. Fenomenologia. Estética.

1 Mestre, professor. Instituto Federal de Educação, Ciência e Tecnologia de Mato Grosso. E-mail: reinaldo.arruda@dmt.ifmt.edu.br 


\section{Introdução}

Neste trabalho busca-se elaborar resultados bibliográficos significativos que vinculam os aspectos da filosofia ontológica de Merleau-Ponty para que possam contribuir com o processo formativo na educaçáo escolar, mais especificamente na disciplina de arte. Acredita-se que os dados teóricos possam indicar caminhos para possíveis exercícios de reflexão a respeito da prática docente com um olhar contemporâneo, não só para obra de arte e o mundo, como também para o aluno.

É pertinente enfatizar que os problemas suscitados por Merleau-Ponty acerca da filosofia da percepção corpórea que está implícita no pensamento e nas obras de Cézanne continuam atuantes e coerentes com a contemporaneidade.

Nesse contexto, este estudo dialoga com alguns teóricos da educaçáo e também com alguns filósofos e estetas contemporâneos que ajudam a pensar possíveis caminhos para o ensino da arte pictórica no contexto escolar. Neste trabalho abordam-se apenas saberes subjacentes à arte contemporânea e à fenomenologia ontológica com o intuito de facilitar a compreensáo das experiências inovadoras trazidas por Merleau-Ponty, que abriu caminho para uma nova concepçáo de pintura, o que convencionou-se chamar hoje de pintura contemporânea.

Lembrando-se que não se trata de uma receita ou mesmo um manual do ensino, mas de um pensar diferente sobre a reflexão a respeito da prática de ensino e de possíveis intervençôes pedagógicas rumo a uma educação da arte democratizada e comprometida com a ampliação dos domínios estéticos e artísticos do tempo vigente.

Este é um trabalho de cunho bibliográfico que se propóe a pensar - a partir da concepçáo da fenomenologia ontológica de Maurice Merleau-Ponty - as implicaçôes da pintura contemporânea no contexto escolar. Suscitamos um questionamento norteador: Em que medida o pensamento desse teórico contribui para ressignificar o olhar sobre a pintura contemporânea no ambiente escolar?

Assim, para compreender o pensamento de Maurice Merleau-Ponty sobre a pintura, foram estudadas as seguintes obras estéticas: $\mathrm{O}$ olho e o espírito (2004); A linguagem indireta e as vozes do silêncio (2004) e A dúvida de Cézanne (2004). Para auxiliar na compreensão da fenomenologia ontológica de Maurice Merleu-Ponty, foram estudados alguns teóricos que investigaram com 
profundidade seu pensamento e outros que articulam a experiência da estética contemporânea no campo educacional com a fenomenologia ontológica.

\section{Concepção do Ser-no-mundo: o aluno como sujeito}

Sabe-se que desde a antiguidade a humanidade se preocupou com a formação humana, não somente para o desempenho do trabalho, mas principalmente para a humanização, isto é, para tornar o ser humano íntegro, justo, ético, emancipado e não alienado. No entanto, até nos dias de hoje, almejam-se os mesmos princípios, por causa das atitudes e comportamentos considerados por muitos como sendo desumanos.

Por isso, é pertinente questionar o papel da escola em relação à formação humana, principalmente na estrutura pedagógica subsidiada pelo racionalismo cartesiano, pois não se pode admitir que a educação se limite tão somente a instrumentalizar o aluno com transmissão de saberes, ensino da técnica e do cálculo. Ao contrário, é necessário possibilitar ao aluno uma formação integral, proporcionando a humanização efetiva (COELHO, 2009).

Sendo assim, o pensamento clássico valoriza excessivamente os aspectos inteligíveis, e nega os aspectos sensíveis, e isso gera um grande problema porque o pensamento puro e imediato não consegue ser parte decisiva da realidade, principalmente no que se refere ao fenômeno artístico, que depende também do sensível. Nesse viés, Barbosa (2008a, p. 63, 64) contribui, quando diz que:

Esta separaçấo cartesiana, do sujeito e do objeto do conhecimento, envia o estudo sobre o sujeito para a área filosófica e o estudo sobre o objeto para a área científica. Não permitindo que ocorra o pensar a unidade na diversidade.

Merleau-Ponty (2011, p. 468), por sua vez, se contrapóe ao pensamento objetivo e enfatiza que esse tipo de pensamento deve ser colocado em dúvida, uma vez que "[...] no pensamento objetivo não há lugar para outrem e para uma pluralidade de consciência".

No pensamento objetivo, o corpo e o mundo são objetos coordenados por relaçóes matemáticas estabelecidas, e o sujeito é um ser passivo. Todavia, o sujeito é perceptivo, é um Ser-no-mundo, é um corpo cognoscente. Dessa forma, a fenomenologia deve voltar ao pensamento “[...] para procurar ali um Logos 
mais fundamental do que o do pensamento objetivo, que lhe dê seu direito relativo e, ao mesmo tempo, o coloque em seu lugar" (MERLEAU-PONTY, 2011, p. 489, 490).

Assim, se o aluno é um sujeito, é um Ser-no-mundo. Por consequência, a sua consciência tem de estar conectada diretamente com o mundo que o envolve. É exatamente por isso que Merleau-Ponty se opóe ao pensamento racionalista, quando se fundamenta na fenomenologia de Husserl para desenvolver estudos que mostram o enraizamento do espírito no corpo, isto é, a consciência corpórea ligada às coisas do mundo.

Segundo Carmo (2002), Merleau-Ponty afirma também que na nossa vida cotidiana, por exemplo, os atos inconscientes predominam sobre os conscientes, e toda função, reflexiva ou não, tem como fundamento a percepção do mundo. Isso porque a todo momento o sujeito realiza movimentos e gestos ancorados em uma crença perceptiva do mundo e das coisas que o cercam, sem que a consciência tenha de pensar constantemente a respeito deles.

A partir deste raciocínio, Merleau-Ponty propóe uma nova filosofia, na qual considera o ser humano, neste caso, o aluno, como Ser-no-mundo, e que propóe a ação de reaprender a olhar o mundo do ponto de vista da subjetividade corpórea perceptiva. No contexto da educação, essa visão ontológica da fenomenologia é importante porque ajuda o educador a pensar o aluno enquanto um sujeito perceptivo na sua relação com o mundo.

Nessa perspectiva, ele também é levado a questionar as concepçóes tradicionais incorporadas no sistema educacional de ensino, principalmente aquelas que envolvem o campo da disciplina de artes visuais, mais especificamente nas aulas de pinturas artísticas. Em relaçáo à percepção, vale destacar o que diz Merleau-Ponty (2004, p. 130): "Na percepção primordial, as distinçóes do tato e da visão são desconhecidas. É a ciência do corpo humano que nos ensina, posteriormente, a distinguir nossos sentidos".

Dessa maneira, percebe-se, no que tange ao aluno e à questão pedagógica, Pillar (2008) compartilha do pensamento e dos preceitos da fenomenologia ontológica de Merleau-Ponty no que se refere à percepção corpórea e à visão do aluno como Ser-no-mundo. Nesse viés, ela enfatiza que é preciso começar a educar o olhar do aluno, se possível desde as séries iniciais para viabilizar práticas pedagógicas que possibilitem a compreensão do modo segundo o qual a visão dele se estrutura e pensar criticamente acerca das imagens que ele produz e que aprecia. 
Enfim, ensinar arte, dentro dos pressupostos da visão contemporânea, com possibilidade de propiciar atividades significativas aos alunos para que estes consigam enriquecer o seu repertório artístico, cultural, histórico e estético.

Nesse contexto, Merleau-Ponty (2004, p. 25), no que diz respeito aos ícones, que estes podem ser os desenhos e pinturas de símbolos e os estereótipos pedagógicos que são comuns na alfabetização, afirma: "Não há mais poder nos ícones. Por mais vivamente que 'nos represente' as florestas as cidades, os homens, as batalhas, as tempestades, a gravura em talho-doce não se lhes assemelha: é apenas um pouco de tinta disposta aqui e ali sobre o papel”.

Concernente ao fazer artístico, Merleau-Ponty (2004) elucida que as crianças são grandes exemplos de improvisaçóes no processo criador pictórico, pois elas aprendem e desenvolvem seus próprios gestos, e propiciam o pretexto de o pintor pintar com o corpo, no caso, a mão. Entáo, acredita-se que qualquer ser humano, neste caso, qualquer aluno, pode pintar.

Merleau-Ponty (2004, p. 81-82) chama-os de pequenos prodígios, uma vez que se comunicam pela expressão corpórea, e diz "como um jovem sombrio pode sempre tirar do seu, contato que o observe com suficiente complacência, alguma pequena esquisitice apropriada a alimentar sua religião de si próprio".

Explica Merleau-Ponty (2004) que a liberdade criadora está vinculada às experiências do mundo vivido, comportamentos, açóes e atitudes vivenciadas pelo Ser, pois a liberdade é o desvencilhar de todas as amarras do passado e viver o presente com um olhar de mundo renovado, como é o caso de Cézanne, que desde criança já indicava os gestos pelos quais as coisas o tocavam.

Por isso, o sentido que Cézanne dará em suas obras pictóricas é que as coisas e os rostos pintados pediram para ser pintados; ele apenas liberou esse sentido, isto é, ele somente exprime o que eles queriam exprimir.

\section{Formação estética pela imagem pictórica}

O pensamento inovador de Merleau-Ponty provocou grande influência na intelectualidade francesa das primeiras décadas do século XX, inserindo o pensar filosófico que se preocupa com o homem muito mais quanto a sua existência, do que em relaçáo a sua essência. Nesse viés, o homem é pensado no contexto natural, cultural e histórico, isto é, como um Ser-no-mundo.

Ao ler Furtado (2009), percebe-se que o pensamento ontológico de Merleau-Ponty está presente e atuante na pós-modernidade, pois a autora 
oportunamente estende a estética para o domínio da educação, mais especificamente, às artes visuais contemporâneas, ao apresentar os princípios da estética de Mikel Dufrenne como possibilidade de formação humana.

Dessa forma, no prefácio da obra de Mikel Dufrenne, denominada Estética e Filosofia, destaca-se a influência de Merleau-Ponty na teoria da estética contemporânea dufrenniana pela relação com a filosofia ontológica da percepção corpórea de Merleau-Ponty.

Nesse sentido, no que concerne às implicaçôes das ideias de Mikel Dufrenne inspiradas nos conceitos filosóficos de Merleau-Ponty, Figurelli (1998, p. 10), ao mencionar o esteta no prefácio da obra, declara: "Ele não esconde seus receios pela direção idealista do pensamento de Husserl. Daí a preferência pela interpretação de Merleau-Ponty, que salienta os aspectos existenciais da fenomenologia".

Nesta conjuntura, é preciso salientar que o problema da educação está relacionado à contínua tensão que envolve duas estruturas de conhecimento, a saber: o olhar sensível e o olhar inteligível que não é similar, mas permite, por meio da curiosidade epistemológica, a experienciar uma consciência autotransformadora.

Furtado (2009) analisa de forma positiva o conteúdo imagético, que tange a valorização da liberdade, alteridade, harmonia entre a dupla dimensão da arte e diz ainda que o diálogo entre tais dimensóes propicia o desenvolvimento solidário, intuitivo, sensível e coletivo no contexto escolar.

Em oposição às concepçóes racionalistas, nas quais se inclui o olhar inteligível, surge como pensamento diferente o método fenomenológico que consiste na suspensão do juízo, ou seja, o olhar para as coisas, como se fosse a primeira vez, desprovido de todos os pressupostos científicos e culturais para apreender as coisas do mundo.

Tal experiência é pré-reflexiva, pois não passa pelo intelecto, e sim, pelos órgãos sensitivos do corpo. Pois é assim que é permitido o acesso às coisas na sua origem, em seu sentido bruto. Nesse contexto, Merleau-Ponty (2004, p. 85) deixa claro que, além do pintor, é possível qualquer pessoa conhecer e apreender as reais coisas do mundo, quando afirma que:

A obra não é feita longe das coisas e em laboratório íntimo, cuja chave só o pintor e mais ninguém possuiria: olhar as flores verdadeiras ou flores de papel, ele se reporta sempre a seu 
mundo, como se o princípio das equivalências pelos quais vai manifestá-lo estivesse desde sempre aí sepultado.

Nesse raciocínio, Mikel Dufrenne explica que o objeto estético é expressivo e portador de um mundo próprio, completamente diferente do mundo objetivo no qual está inserido. Assim, ainda diz que o objeto se manifesta constantemente com o observador e com os outros objetos, pois ele exprime o sentido do seu corpo, ou seja, um espírito que responde e que solicita a interlocução com o nosso espírito e força a relação de amor fraterno. $\mathrm{O}$ autor (1998, p. 85 ) endossa que: "Escutar a linguagem do objeto estético, ler a expressão que o informa, e entrar mais profundamente em sua intimidade do que através do conhecimento do intelecto".

Com relação ao prazer afetivo com o objeto estético, Furtado (2009) salienta uma passagem de Mikel Dufrenne, o qual acredita que o prazer propiciado pela apreciação do objeto estético é mais sofisticado do que o prazer que satisfaz apenas as necessidades fisiológicas do corpo, que é o instrumento utilizado para desvendar a presença do objeto estético, e, ao mesmo tempo, a consciência, que atribui sentido ao mundo e à existência humana.

Nesse viés, ao considerar a percepção estética como possibilidade de informação de linguagem, Carmo (2002, p. 95) complementa com ideias ontológicas ao explicitar que:

Para Merleau-Ponty a respeito da linguagem tem como fundamento tratá-la como uma modalidade do corpo, e não como uma operação da consciência pura. Nesse sentido, a consciência corpórea faz parte do mundo da experiência pré-reflexiva e é, portanto, considerada como uma atitude sublime de um pensamento mais elevado.

É no contexto da fenomenologia ontológica e no exercício de percepção estética que se possibilita transformar o campo educacional tão prejudicado pela fragmentação dos saberes no que tange à maneira de ver e pensar o mundo. E ainda, superar o pensamento imediato que é o grande desafio do ensino formal atual, o qual está a cargo com maior destaque na filosofia contemporânea que prima principalmente pela abstração subjetiva da percepção, como forma de apreensão e articulação da realidade. 
Nesse sentido, busca-se uma educação voltada para o exercício da criatividade, da imaginação, da análise com o intuito de refletir o sistema disciplinar e curricular do ensino nacional, que transmite conhecimento meramente técnico e de compreensão pela memorização. A partir disso, pretende-se fazer uma intervenção pedagógica significativa, que seja pautada por uma relação de reciprocidade entre sujeito/objeto, professor/aluno. Em síntese, almeja-se instituir, de fato, uma educação emancipadora, solidária e democrática.

Assim, o mundo da percepção para Merleau-Ponty (2004) não é o que se conhece, pois para ele isso é pura ilusão. E ainda salienta que, enquanto insistir em ver as coisas por meio da visão direta da consciência pura das necessidades imediatas do cotidiano, o mundo da percepção permanece invisível para o Ser. É nisso que consiste a função da filosofia fenomenológica de Merleau-Ponty, ou seja, retirar a fumaça que ofusca o olhar do Ser, para que ele possa mirar diretamente as coisas do mundo.

Dessa forma, ele consegue voltar às próprias coisas do mundo, isto é, na origem, em seu estado bruto e selvagem. Portanto, Merleau-Ponty afirma que para olhar o mundo assim, de maneira renovada, é necessário recorrer à arte de seu tempo, mais precisamente, à pintura.

\section{Educação do olhar corpóreo e a apreensão do mundo pela arte pictórica}

A visão ocular, ou seja, a visão pura da consciência, é muito limitada, pois o que se pode ver é o que se tem condições de compreender, e o que é significativo. Os geneticistas sabem muito bem que o cérebro consegue assimilar apenas uma pequena parte das muitas informaçóes que o ser humano recebe.

Da mesma forma, o olhar não é instantâneo, pois ele capta algumas das múltiplas informaçóes visuais presentes no dia a dia e precisa de processos intelectuais complexos para visualizar as coisas. Na verdade, náo se consegue aprender o mundo tal como ele é, apenas constroem-se mediaçóes, filtros, sistemas simbólicos para conhecer de forma insuficiente o que está ao redor e a si próprio (PILLAR, 2008).

Para Merleau-Ponty, nos comportamentos cotidianos os atos inconscientes sobrepujam sobre os atos conscientes, e toda prática humana, reflexiva ou não, tem como princípio a percepção das coisas do mundo. A atividade 
reflexiva das interrogações do mundo, colocada em prática pelos filósofos, é apenas passageira e artificial.

Isso porque, a todo momento, o ser humano realiza movimentos, gestos, amparados em uma crença perceptiva das coisas do mundo que nos cercam, sem que a consciência tenha que pensar a todo instante sobre eles. O que se percebe não é um mundo idealizado pelo pensamento, não é um mais um corpo ou uma paisagem absoluta no espaço, como veem os cartesianos.

Merleau-Ponty (2004, p. 16) ensina que a visão, o corpo e o movimento estão imbrincados no olhar e, portanto, no Ser. A visão depende do corpo, que é resultado de visão e movimento. "Meu corpo móvel conta com o mundo visível, faz parte dele, e por isso posso dirigi-lo no visível. Por outro lado, também é verdade que a visão depende do movimento".

E ainda, o movimento é a sequência natural e também o amadurecimento de uma visão. Nesse processo, o corpo se move e o movimento se desenvolve; o corpo não se ignora e nem é cego para si; ele está preso no tecido do mundo. Sendo assim, "o enigma consiste em meu corpo ser ao mesmo tempo vidente e visível. Ele, que olha todas as coisas, pode também se olhar, e reconhecer no que vê então o 'outro lado' de seu poder vidente. Ele se vê vidente" (MERLEAU-PONTY, 2004, p. 17).

Por meio da percepção é possível o vínculo do ser humano com as coisas do mundo, isto é, pode-se perceber o mundo pelos órgáos sensitivos do corpo. Assim, ao olhar a natureza, automaticamente, estabelece contato com todas as coisas, pois as relaçóes perceptivas se dão apenas diante do mundo existente e acontecem quando o sujeito adentra no mundo.

Desta maneira, a relação do Ser com o mundo nos domínios da percepção torna possível a apreensão das coisas existentes (BUORO, 1996). A respeito do contexto da percepção pré-reflexiva, Merleau-Ponty (2004, p. 20) diz:

Ela faz algo completamente distinto, quase o inverso: dá existência visível ao que a visão profana crê invisível, faz com que não tenhamos necessidade de 'sentido muscular' para ter a voluminosidade do mundo. Essa visão é devoradora, para além dos 'dados visuais' dá acesso a uma textura do ser da qual as mensagens sensoriais discretas são apenas as pontuações ou as cesuras, texturas que o olho habita como homem sua casa. 
Pode-se dizer que essa ação é importante para a educação do olhar corpóreo porque possibilita ao aluno o exercício de aprender a olhar a obra, não como se olha uma coisa fixa em um lugar determinado, mas aprender a olhar além do que se vê, além das cores, luzes e linhas. Conforme Merleau-Ponty (2004), nossos olhos têm o dom do visível e esse dom se conquista pelo exercício, pois o olho vê o mundo e só se aprende vendo e por si mesmo.

Nesse contexto, Buoro (1996) acrescenta que o olhar do aluno para o conteúdo pictórico propicia a descoberta da demonstração espacial e das relaçóes formais em elementos que o aluno destaca e reorganiza segundo um critério próprio e individual. Estes exercícios são predominantemente reprodutivos, narrativos e descritivos. $\mathrm{O}$ aluno aprende a ler, a reconhecer e a recriar a partir deles.

A criação e transgressão do código a partir do conhecimento só acontecerá no momento em que o aluno já tiver algum domínio da linguagem plástica, pois nas faixas etárias iniciais eles ainda estão no percurso de construir e ampliar o repertório básico da percepção do mundo.

Em relação aos elementos expressivos da pintura, Merleau-Ponty (2004, p. 22) diz: "Esse olhar pré-humano é o emblema do olhar do pintor. Mas completamente que as luzes, as sombras e os reflexos, a imagem especular esboça nas coisas o trabalho da visão".

A questão de buscar entender a visibilidade do pintor materializada nas imagens pictóricas mostra-se pertinente como temática central de um projeto progressista educacional que almeja construir conhecimento a partir das artes plásticas, pois conduz às experiências de aquisiçáo de um repertório imagético verdadeiro, que mostra verdadeiramente as coisas do mundo.

Desse modo, o processo da leitura das imagens do mundo apreendida na pintura vai nutrir de imagens a imaginação do aluno e desenvolver o seu repertório imagético, consequentemente o cultural, artístico e estético, possibilitando as recombinaçóes e produçôes de novas imagens do mundo por meio da imaginação criadora (BUORO, 1996).

Assim, Merleau-Ponty resgata a importância do corpo como fundamentação para o conhecimento, pois o corpo foi esquecido pela filosofia clássica que o negara com veemência. Ainda a respeito do corpo, Carmo (2002, p. 82) explica que: "Merleau-Ponty procura reabilitá-lo, não apenas antropologicamente. Trata-se muito mais de reconhecer no corpo uma fundamentação para o conhecimento". 
Portanto, segundo Merleau-Ponty (2004, p. 99), não é o "espírito" que ocupa lugar no corpo e prenuncia aquilo que se vê. Mas são os próprios olhares do Ser, é uma sinergia, ou seja, um esforço coletivo e simultâneo do olhar corpóreo que mira o objeto eminente, e nunca as nossas correçóes do intelecto teriam tempo hábil e precisão suficiente para compreender o verdadeiro cálculo da conclusão da circunstância real.

Nesse ponto de vista, o olhar corpóreo, de mão e de corpo em geral, é um organismo sistêmico voltado para o reconhecimento do mundo, capaz de transpassar a distância, de revelar o futuro, de desenhar coisas do mundo de formas inacreditáveis.

Nesse sentido, Merleau-Ponty (2004, p. 45) comenta acerca dos elementos expressivos da pintura, quando diz:

Já que a profundidade, cor, forma, linha, movimento, contorno, fisionomia são ramos do Ser, e cada um deles pode trazer consigo toda ramagem, não há em pintura problemas separados, nem caminhos verdadeiramente opostos, nem soluçóes parciais, nem progressos por acumulação, nem opção sem retorno.

Nesse viés, para o autor, o espírito do mundo é o próprio Ser vivo, a partir do momento em que se move no mundo, e, ao mesmo tempo, sabe olhar as coisas da natureza. Essas atitudes simples e cotidianas revelam o segredo da linguagem expressiva, pois ao movimentar o corpo, mesmo sem conhecer as funçôes da motricidade, da interferência dos órgãos do sistema nervoso, o artista ecoa seu estilo por todos os aspectos da matéria que ele pinta.

Dessa forma, o pintor e qualquer um que pinta é inspirado pelo olho objetivo e o elemento corporal faz a sua funçáo de conectar-se com ele.

Merleau-Ponty (2004 p. 99) enfatiza que: "Qualquer percepção, qualquer ação que a suponha, em suma, qualquer uso humano do corpo já é expressão primordial”. Assim, ao olho, tudo transita no mundo da percepção e do gesto, mas o corpo físico submete-se às exigências dos impulsos sensitivos que não deixam de suscitar nele emanaçôes dos fenômenos naturais. 


\section{Arte pictórica: filosofia da visibilidade?}

Merleau-Ponty aproximou a arte, em especial a pintura e a filosofia, da fenomenologia ontológica. Ele almeja que a filosofia desempenhe a mesma função da pintura, pois, embora ambas busquem a percepção como caminho para a verdade do mundo e da existência humana, a obra pictórica suscita o pensamento que interessa a filosofia.

Dessa maneira, a filosofia seria compreendida também como uma criação ao comunicar a experiência muda em si mesma. Merleau-Ponty (2004, p. 43) ainda diz: "Um pintor não pode consentir que nossa abertura ao mundo seja ilusória ou indireta, que o que vemos náo seja o mundo mesmo, que o espírito só tenha de se ocupar com seus pensamentos ou com outro espírito".

Nesse sentido, a partir da declaração de Merleau-Ponty (2004), segundo a qual a pintura seria uma verdadeira filosofia da visibilidade, pode-se entender como uma relevante contribuição ao contexto escolar, pois assim ele aponta a pintura como possibilidade de formação humana.

Em uma de suas passagens na obra $A$ linguagem indireta e as vozes do silêncio, ele lembra oportunamente que os escritores não devem subestimar o trabalho pictórico, tampouco as pesquisas do pintor, pois ele acredita que o esforço que é imprimido no processo de plasmar as tintas é tão parecido com um esforço do pensamento, e que por meio da imagem pictórica exprime-se também uma linguagem humana.

Para Merleau-Ponty (2004), a pintura não é uma construção mecânica da natureza ou de um mundo exterior, apreendendo as coisas do mundo pela percepção do pintor. A partir disso se explicam as características estéticas de elementos desarticulados e não lapidados.

Merleau-Ponty (2004, p. 37) diz que “[...] parece a voz da luz”. Ele ainda pontua que a pintura tem uma história de esforços para distanciar da ilusão da pintura clássica realista em busca de suas próprias características, que hoje tem significado metafísico.

Nesse sentido, trabalhar a pintura contemporânea no contexto escolar é necessário, afinal ela está imbuída de percepçôes expressivas, estéticas e estilos do tempo existentes, importantes para o desenvolvimento estético, cultural e artístico dos alunos. Porém, é pertinente repensar o período contemporâneo do conceito cronológico da história. 
Em suma, há uma confusão instalada, e isso dificulta a assimilação de ambos os princípios e, consequentemente, a aprendizagem. Sendo assim, talvez, seria mais adequado utilizar o termo contemporâneo na acepção da contemporaneidade atual, ou seja, considerar as pinturas contemporâneas como aquelas que são produzidas neste momento em que o público as olha.

Por causa disso, seria pertinente questionar também se a pintura contemporânea não seria uma continuidade da pintura dos modernistas de vanguarda, mais voltada para a comunicação, análise estética, para uma prática e teoria mais inclusivas e democráticas. Acerca do modelo da pintura moderna, Merleau-Ponty (2004, p. 88) diz que:

A pintura moderna, como o pensamento moderno em geral, obriga-nos a admitir uma verdade que não se assemelhe às coisas, que não tenha modelo exterior, nem instrumentos de expressão predestinados, e que seja, contudo, verdade.

Sendo assim, acredita-se que a pintura contemporânea (que está implicada com as pinturas do passado) é uma possibilidade de formação humana, ou seja, conhecer, contextualizar e refletir a respeito dos trabalhos e do pensamento de grandes mestres da pintura, tais como Cézanne, em foco nesta pesquisa, pois sua experiência pictórica possibilita ampliar a fundamentação teórica e prática para subsidiar um ensino-aprendizagem de arte mais significativo para o aluno.

Contudo, é oportuno lembrar que a reflexão da presente pesquisa não partilha das concepçóes duchampianas que, como o próprio Duchamp anunciara de antiarte, pois esta tendência ignora e tem como proposiçáo acabar com a pintura em geral e seus valores, como o estilo, o artista, a interpretação da realidade do mundo, o conteúdo intencional da pintura e o canal de transmissão, etc.

Sem a intenção de desmerecer esta tendência, que possui muitos adeptos e muitos trabalhos escritos que lhe são dedicados como referência de numerosos artistas da atualidade. Sem esquecer também as contribuições significativas de oposição no contexto da Primeira Grande Guerra Mundial, mas o movimento dadaísta (antiarte), segundo Cauquelin (2005), é também alvo de muitas críticas.

Portanto, a respeito da originalidade e do estilo do pintor, Merleau-Ponty (2004) declara sua opinião quando enfatiza que o estilo não é uma técnica, 
é a própria linguagem do artista pela qual ele desenvolve sem saber, isto é, refere-se à capacidade de expressar as suas experiências no mundo vivido.

Para o autor, o estilo expressa o sentido de sua produção artística. Merleau-Ponty (2004) ainda explica que o pintor, o aprendiz, ou qualquer aluno, e todo o passado da prática pictórica estáo interligados a um costume tradicional que exige seu estilo ao domínio da pintura.

Contudo, é notória a grande contribuição do pensamento da fenomenologia ontológica de Merleau-Ponty para a educação, mais especificamente, para a ressignificação da pintura contemporânea, pois os conteúdos imagéticos ampliaram-se muito nas últimas décadas, e muitas dessas diversidades de estéticas, estilos, conteúdos artísticos que apresentam ainda características do realismo tradicional do pensamento clássico, já foram abordadas nesta pesquisa, tais como imitação da natureza, ou seja, a pintura clássica é uma falsa afirmação de expressão da realidade e o olhar direto é simplesmente ilusão do mundo real.

Nesse viés, o pensamento merleau-pontyano torna-se uma possibilidade de reflexão e ação da visibilidade filosófica em relação à realidade do mundo atual e da existência da contemporaneidade, pois suas ideias podem suscitar uma nova maneira de ver e interpretar a realidade do mundo e da existência humana.

Portanto, neste estudo, constata-se que o pensamento de Merleau-Ponty vive e está em consonância com muitos aspectos do segundo manifesto da arte contemporânea, ao qual se opuseram as ideias duchampianas.

Nessa direção, a arte de rua e as concepçóes pictóricas de Merleau-Ponty e Cézanne são de períodos distintos. Porém, como diz Cauquelin (2005), não estão em conflito, estão lado a lado. Inclusive, até compartilham de fórmulas e valores do fazer pictórico, como a originalidade, a expressão, a valorização do estilo, do artista, da interpretação da realidade, da liberdade criadora, do gesto, do corpo, da percepção, da sensação, da estética vinculada à arte. Em suma, a pintura moderna e os modelos de tendências artísticas atuais estáo constituindo dispositivos complexos em comum, que estão em constante transfiguração.

Nesse sentido, constata-se nesta pesquisa que o pintor, para ser contemporâneo, precisa perceber a essência do universo das pinturas, inclusive, as do passado, pois todas as pinturas, inclusive a clássica, pertencem ao mesmo universo da cultura humana, e por isso suas características não estão mortas e acabadas.

A essência da pintura realista reaparece em algumas tendências atuais de forma renovada e com outro propósito de expressão, agora a visibilidade está 
voltada para os preceitos e sensibilidades pictóricas do nosso tempo, como as pinturas urbanas e o hiper-realismo exemplificados na pintura contemporânea da artista plástica de Nova Jersey (EUA) chamada Alyssa Monks, uma pintora criativa e detentora de um estilo admirável e uma técnica sutil que mistura em suas obras características hiper-realistas misturadas com características obscuras quase abstratas em grande parte da obra, é como se ela representasse o visível e o invisível do Ser ao mesmo tempo.

Nesse sentido, Carmo (2002, p. 132) diz: "O tema da liberdade, por exemplo, faz-se presente nas abordagens de Merleau-Ponty e para isso ele recorre frequentemente às análises das atuaçôes dos pintores”.

Por fim, nesse contexto, a filosofia ontológica de Merleau-Ponty é uma possibilidade de fundamentar a prática pictórica e compreender a pintura como criação, reflexão, prefiguração e transfiguração do mundo objetivo e subjetivo por meio da percepçáo corpórea, que vê e apreende tanto as coisas visíveis como as invisíveis do mundo.

Como acredita Merleau-Ponty (2004), que o pintor, seja ele quem for, desempenha uma atividade mágica da visão totalmente desprovida de sentido. Portanto, a contribuição maior da filosofia ontológica de Merleau-Ponty é o questionamento do pensamento racionalista como verdade absoluta e, também, a da pintura clássica como a exata visibilidade do mundo.

Espera-se que este trabalho de pesquisa possa subsidiar a reflexão e a ação mediadora do ensino-aprendizagem da arte na escola, principalmente, nas intervençóes pedagógicas da prática e na concepção da pintura contemporânea no que tange ao visível e ao invisível, ao figurativo e ao abstrato, à pintura do passado e à pintura do presente.

A razão da escola não é preparar recursos humanos, é ensinar a pensar as ideias e a realidade. Isso é fundamental para a constituição e afirmação da existência humana.

Para Coêlho (2012), o que faz a escola e a aula serem o que são não é a socialização de um saber considerado verdadeiro, mas sim o trabalho de formar os alunos no e pelo pensamento, possibilitando a todos uma convivência efetiva com a leitura, a escrita, as obras de cultura da humanidade, com ideias e argumentos, com um saber interrogado, compreendido e pensado inclusive nas suas implicações e com a beleza das formas e nas artes.

Assim, uma aula de arte, ou mais especificamente, de pintura, não pode se limitar a uma exposição de preceitos e técnicas pictóricas. Deve ser uma 
aula que provoca a inteligência dos alunos, convidando-os a participar do exercício intelectual de interrogar, de investigar, de provocar a imaginação, a criatividade, a percepção, a observação, de criar novas realidades, explicar, compreender. Os alunos devem ser ensinados a pensar o mundo em pinceladas que não se completam e nem se dão por acabadas.

\section{Considerações finais}

Esta pesquisa aponta novos caminhos para possíveis exercícios de ressignificação do olhar do professor de arte e consequentemente do aluno. Porém, é importante considerar também o aluno como um Ser-no-mundo, pois ele não é objeto vazio que precisa ser preenchido. Pelo contrário, ele interage e constrói experiências no meio vivido, e possui a capacidade de exercitar a experiência da visibilidade do mundo e com possibilidade de desenvolver a apreensão pictórica através de experiência vivida.

É nesse viés do pensamento da fenomenologia ontológica de MerleauPonty e no exercício da percepção estética proposta que possibilita a mais notória contribuição da filosofia para o campo educacional, tão prejudicado pela fragmentação dos saberes promovida pelo pensamento racional cartesiano de ver e pensar o mundo.

Pode-se dizer que essa ação é importante para a educação do olhar corpóreo porque possibilita ao aluno o exercício de aprender a olhar a obra, não como se olha uma coisa fixa em um lugar determinado, mas aprender a olhar além do que se vê, além das cores, luzes e linhas. Conforme Merleau-Ponty, nossos olhos têm o dom do visível e esse dom se conquista pelo exercício, pois o olho vê o mundo e só se aprende vendo e por si mesmo.

Ademais, constata-se neste estudo que a pintura contemporânea ainda está obscura, pois não é compreendida pelo público porque se mistura com as manifestações artísticas da pintura moderna. Atualmente, se instalou uma grande confusão no campo das artes, porque a pintura moderna ainda em vigor não propicia o discernimento da pintura contemporânea, uma vez que ambas se misturam, e, muitas vezes, até dialogam e se harmonizam entre si.

$\mathrm{Na}$ verdade, percebe-se que a pintura contemporânea ainda não dispôs de um tempo de organização conceitual, tampouco de critérios totalmente definidos. Portanto, muitas dessas tendências atuais procuram justificar seus trabalhos artísticos fora dos domínios artísticos já consolidados. Mesmo assim, 
é possível, de longe, vislumbrar a chegada de uma nova realidade no campo artístico expressada em outras manifestações artísticas, como instalação, performance, intervenção, etc., porém com menos intensidade na pintura.

Nesse viés, é pertinente repensar o período contemporâneo do conceito cronológico da história humana, pois, ao se considerar o período moderno todo o século XX, se trata apenas de pintura moderna, mas a pintura contemporânea, embora ofuscada, existe, e está entrelaçada com a pintura moderna, transfigurada para o nosso tempo.

Entretanto, não estão em conflito, pois esses modelos de concepções pictóricas diferentes estão constituindo dispositivos complexos em comum, que estão em constante transfiguração. E é por isso que possuem o mesmo valor expressivo e estético neste trabalho de pesquisa.

A pintura se manifesta em diferentes olhares, mas para Merleau-Ponty não houve uma evolução única e linear das representações pictóricas entre o passado e o presente, portanto não existe uma pintura melhor que a outra, todas pertencem ao mesmo universo.

É por isso que é pertinente questionar tanto o pensamento racionalista cartesiano, como também a pintura clássica que está estruturada nesse mesmo viés de pensamento. Isso explica porque não existe um consenso na definição da arte, pois é necessário considerar o tempo, espaço e cultura em que ela foi produzida.

A fenomenologia é um método filosófico contemporâneo, que tem como premissa mostrar verdadeiramente as coisas do mundo. É um olhar diferente dos pressupostos da ciência racionalista cartesiana, que apreende o mundo pelo intelecto e o olhar direto e objetivo para a natureza.

A percepção sensível (corpórea) proposta por Merleau-Ponty, que tem em Cézanne seu pintor por excelência, e a pintura como verdadeira filosofia da visibilidade, consistem em mostrar o mundo na sua origem mais profunda, isto é, o mundo não familiarizado da percepção corpórea, onde as coisas se apresentam de forma confusa e quase indistinta, um lugar onde os pintores já habitam e possuem a capacidade de apreender a visibilidade deste lugar pré-espacial.

Neste estudo, constata-se que o pensamento de Merleau-Ponty ainda é atuante e coerente com os aspectos do movimento norte-americano (Nova York e Filadélfia) que também influenciou fortemente a arte contemporânea, o qual se opôs às ideias duchampianas. 
Dentre as novas produçóes pictóricas contemporâneas que dialogam com as ideias de Merleau-Ponty, referenciado em Cézanne, destacam-se, como exemplo, a arte urbana que emana do povo para o próprio povo sem nenhum compromisso comercial, e possui um único intuito, que é o de comunicar a visibilidade do mundo associado aos problemas existenciais da sociedade.

Contudo, a pintura contemporânea não se limita tão somente à arte urbana, na contemporaneidade, pois todas as pinturas, tanto a clássica, quanto a moderna, se misturam e não estão em conflito. Pelo contrário, estáo implicadas, lado a lado e trocam fórmulas. É assim que se constitui a pintura contemporânea, pois ela é portadora da essência das experiências pictóricas do passado, inclusive dos valores estéticos da pintura clássica realista que reaparece com um olhar renovado, mais voltada para o campo da estética sensível e para a comunicabilidade.

Nesse viés, as possibilidades imagéticas de transfiguraçôes inovadoras no domínio da diversidade estéticas são imensas, pois estão em desconstrução, construção e reformulação constante.

Por fim, a filosofia ontológica de Merleau-Ponty é uma possibilidade de fundamentar a prática pictórica e compreender a pintura como criação, reflexão, ressignificação e transfiguração do mundo objetivo e subjetivo por meio da percepção corpórea, que vê e apreende tanto as coisas visíveis como as coisas invisíveis do mundo.

\section{REFERÊNCIAS}

BARBOSA, A. M. As mutações do conceito e da prática. In: BARBOSA, A. M. (Org.). Inquietaçóes e mudanças no ensino da arte. 5. ed. São Paulo: Cortez, 2008 a p. 13-25.

BUORO, A. B. O olhar em construçáo: uma experiência de ensino e aprendizagem da arte na escola. São Paulo: Cortez, 1996.

CARMO, P. S. Merleau-Ponty: uma introduçáo. São Paulo: Educ, 2002.

CAUQUELIN, A. Arte contemporânea: uma introdução. São Paulo: Martins Fontes, 2005. COÊLHO, I. C. (Org.). Qual o sentido da escola? Campinas, SP: Mercado de Letras, 2012. COELHO, I. Filosofia, educação, cultura e formação. In: COELHO, I. (Org.). Educaçáo, cultura e formaçáo: o olhar da filosofia. Goiânia: Ed. PUC Goiás, 2009. p. 7-14.

DUFRENNE, M. Estética e filosofia. 3. ed. São Paulo: Editora Perspectiva S.A., 1998.

FERRAZ, M. H. C.; FUSARI, M. F. R. Arte na educaçáo escolar. 2. ed. São Paulo: Cortez, 1993. 
FIGURELLI, R. Introdução. In: DUFRENNE, M. Estética e filosofia. 3. ed. São Paulo: Editora Perspectiva S.A., 1998. p. 07-19.

FURTADO, R. M. M. A experiência estética como experiência formadora. In: COÊLHO, I. M. (Org.). Educaçáo, cultura e formaçáo: o olhar da filosofia. Goiânia: Ed. PUC Goiás, 2009. p. 139-162.

MERLEAU-PONTY, M. Fenomenologia da percepçáo. Tradução de Carlos Alberto Ribeiro de Moura. 4. ed. São Paulo: WMF Martins Fontes, 2011.

. O olho e o espírito: seguido de A linguagem indireta e as vozes do silêncio e A dúvida de Cézanne. Tradução: Paulo Neves e Maria Ermantina Galvão Gomes Pereira. Prefácio de Cláudio Lefort. Posfácio de Alberto Tassinari. São Paulo: Cosac Naify, 2004.

PILLAR, A. D. A Educação no Olhar no Ensino da Arte. In: BARBOSA, A. M. (Org.). Inquietaçóes e mudanças no ensino da arte. 5. ed. São Paulo: Cortez, 2008. p. 71-84. 